\title{
Correlation of Arterial Blood Gas Value with Outcome of Patient Admitted with Acute Exacerbation of Chronic Obstructive Pulmonary Disease
}

\author{
Santosh Gautam ${ }^{1}$, Shiva Raj KC ${ }^{2,6}$, Milesh Jung Sijapati ${ }^{3}$, Purnima Gyawali ${ }^{4}$, \\ Geetika KC ${ }^{2}$, Sukh Bahadur Gurung ${ }^{5}$ \\ ${ }^{1}$ Department of Internal Medicine, KIST Medical College Teaching Hospital, Imadol, Lalitpur, Nepal \\ ${ }^{2}$ Department of Pathology, KIST Medical College Teaching Hospital, Imadol, Lalitpur, Nepal \\ ${ }^{3}$ Department of Internal Medicine, KIST Medical College Teaching Hospital, Imadol, Lalitpur, Nepal \\ ${ }^{4}$ KIST Medical College Teaching Hospital, Imadol, Lalitpur, Nepal \\ ${ }^{5}$ Department of Pharmacology and Therapeutics, KIST Medical College Teaching Hospital, Imadol, Lalitpur, Nepal \\ ${ }^{6}$ Department of Pathology and Laboratory Medicine, Patan Academy of Health Sciences, Lagankhel, Lalitpur, Nepal
}

\section{ABSTRACT}

Introduction: The outcome of Chronic Obstructive Pulmonary Disease depends upon the partial pressure of oxygen and carbon dioxide This study was aimed to find the role of arterial blood gas parameters during the length of hospital stay among patients admitted for chronic obstructive pulmonary disease with acute exacerbation.

Materials and Methods: This was an observational study conducted in KIST Medical College Teaching Hospital from February 2017 to August 2019. Patients admitted with the chronic obstructive pulmonary disease were evaluated. Demographic data as well as oxygen saturation $\left(\mathrm{SpO}_{2}\right)$, pulmonary function test, and arterial blood gas analysis were recorded and analyzed.

Results: Among 112 patients, the female to male ratio was 1.38 : 1 with $84.8 \%$ over 60 years of age. One-third of patients $(\mathrm{n}=38)$ had exposure to both tobacco smoking and biomass and of them, $86.8 \%$ were females. Mean $\mathrm{SpO}_{2}$ was $75.9 \%$ and mean $\mathrm{FEV}_{1}$ was $0.92 \mathrm{~L}(\mathrm{SD}=0.295)$ and significant association was found $(\mathrm{p}<0.001)$ between them. Furthermore, $70(62.5 \%)$ patients had type I respiratory failure and 42 patients $(37.5 \%)$ had type II respiratory failure. Patients with type II respiratory failure and hypercapnic patients had prolonged hospital stay with significant p-value $(\mathrm{p}<0.001)$. Similarly, significance was observed in the $\mathrm{p}$-value for acidic blood $\mathrm{pH}$, which was $<0.05$.

Conclusions: Increased length of hospital stay is seen in patients with acute exacerbation of chronic obstructive pulmonary disease with type II respiratory failure. Hence, aggressive early management to correct hypercapnia may lead to decreased hospital stay along with a better outcome. Thus hypercapnia should be considered as one of the important criteria to flag the patient and manage accordingly.

Keywords: Biomass; Cigarette; Hospital stay; Hypercapnia; Oxygen saturation; Respiratory failure
Correspondence:

Dr. Shiva Raj KC, MD

Associate Professor, Department of Pathology

Patan Academy of Health Sciences, Lagankhel,

Lalitpur, Nepal.

ORCID ID: 0000-0002-2107-5322

Email: shivarajkc074@gmail.com

Submitted: $1^{\text {st }}$ November 2020 Accepted: $18^{\text {th }}$ December 2020

Source of Support: None

Conflict of Interest: None

Citation: : Gautam S, KC Shiva R, Sijapati MJ, Gyawali P, KC Geetika, Gurung SB. Correlation of Arterial Blood Gas Value with Outcome of Patient Admitted with Acute Exacerbation of Chronic Obstructive Pulmonary Disease. NMJ 2020;3(2):33842. DOI 10.3126/nmj.v3i2.34880 


\section{INTRODUCTION}

Chronic obstructive pulmonary disease (COPD) is a common non-communicable disease, with a strong association with cigarette smoking and exposure to household smoking. The national data of 2017 showed that, among non-communicable diseases, COPD was the second most common cause of death ( $9.8 \%$ of total deaths) only preceded by Ischemic heart disease. ${ }^{1}$ Due to its chronicity, physical disability, and disease-associated mortality, its impact on the health economy is considerable.

In 2016, 251 million cases of COPD have been reported globally by the Global Burden of Disease Study reports. ${ }^{2}$ The mortality rate due to COPD, in 2015, is estimated to be 3.17 million worldwide comprising approximately $5 \%$ of all deaths. 1 The highest prevalence rate was estimated in the American continent (15.2\% in 2010). In East Asia, the estimated prevalence of COPD is as compared to South Asia, which is $9.7 \%$ in 2010. This figure is the lowest across the globe. ${ }^{3}$ More than $90 \%$ of COPD deaths occur in low and middle-income countries. ${ }^{2}$ World Health Organization (WHO) report on the global tobacco epidemic projected a $160 \%$ increment in COPD- associated mortality in the Southeast Asian region. ${ }^{4}$ The prevalence of COPD is in a decreasing trend but remains very high. ${ }^{5}$

Several risk factors attributing to the poor outcome on a stable COPD patient have been identified. Among them, forced expiratory volume in 1 second $\left(\mathrm{FEV}_{1}\right)^{6}$, body mass index, and exercise tolerance are established. ${ }^{7}$ Besides these factors, infections also play a pivotal role. The BODE Index was designed to assess COPD prognosis ${ }^{8}$ which included BMI, $\mathrm{FEV}_{1}$, a modified Medical Research Council dyspnoea score, and the 6-min walk distance. Overall, the BODE Index was more effective than FEV alone at predicting the risk of all-cause or respiratory mortality. ${ }^{9}$

Amongst chronic obstructive respiratory complications, respiratory failure is a frequent occurrence. The presence or absence of hypoxemia/hypercapnia dictates the good or worse outcome of the disease process. ${ }^{10}$ Hence, identification of the various factors and their association may enable clinicians to assess the life expectancy of the patient much better. This is extremely important, to implement more individualised and effective treatment strategies. The current study aimed to investigate the arterial blood gas parameters as a factor associated with the length of hospital stay of patients admitted for COPD with acute exacerbation.

\section{MATERIALS AND METHODS}

This was a prospective, observational study conducted in the Department of Internal Medicine, and Department of Pathology, KIST Medical College Teaching Hospital. After approval from the Institutional Review Board- KIST Medical College, data were collected from the patients admitted with the diagnosis of acute exacerbation of COPD (AECOPD) from February 2017 to August 2019. Any known patient with COPD presenting with a sustained increase in cough, sputum production, and/or dyspnea was considered as AECOPD. The patients were explained regarding the research and written consent was obtained. Patients not requiring all the necessary investigations or not willing to participate were excluded from the study.
A proforma including social demographics, history of associated diseases, smoking history, house-hold smoke exposure, and clinical findings of crepitation, wheeze, $\mathrm{SPO}_{2}$ was developed. Someone, who smokes any tobacco product is considered a smoker. Similarly, anyone exposed to house-hold smoke (wood, animal dung, crop residues, and so forth) during cooking or for warming houses in inefficient ventilation based on the duration of daily exposure for years are considered exposed to house-hold smoke. Patients with a history of biogas exposure for at least one hour daily for one year were included in the study.

Investigations done were total leukocyte count with differential count, pulmonary function test (PFT), and arterial blood gas (ABG) analysis, sputum/blood/urine culture. PFT was done once the acute exacerbations were resolved and the patient regained almost the previous functional status as per mMRC Dyspnea Scale. ABG was performed at the time of admission and after the resolution of acute exacerbation. Also included in proforma were the use of steroids and the total day of hospital stay.

These findings were collected, entered, and analyzed in a proforma, Microsoft Excel, and SPSS vs.27 respectively. Percentage, mean, correlation, and Logistic Regression were analyzed. P-value was calculated with the Chi-square test and p-value $<0.05$ were considered significant.

\section{RESULTS}

During the study period, a total of 203 patients of COPD were admitted to the medical department of KIST Medical College Teaching Hospital. Among these patients, 112 patients either consented for involvement in the study or met the inclusion criteria. Of these 112 study population, 47 were male and 65 female, with female to male ratio of 1.38: 1 . Most of the patients were older than 60 years $(\mathrm{n}=95 ; 84.8 \%)$ and besides, 25 patients $(22.3 \%)$ were older than 79 years. Age ranged from 43 years to 93 years with a mean age of 69.65 years. (Table 1) Among the male, 30 out of $47(63.8 \%)$ were between 60 and 79 years. Likewise, in the female group, 40 out of $65(61.5 \%)$ were between 60 and 79 years.

Table 1: Demographic and other relevant findings among the study population $(n=112)$

\begin{tabular}{ll}
\hline Mean Age & $\mathbf{6 9 . 6 5}$ years $(\mathrm{SD} \pm \mathbf{1 0 . 7})$ \\
\hline Gender & \\
Male & 47 \\
Female & 65 \\
Smoker & \\
Male & $47 / 47$ \\
Female & $59 / 65$ \\
\hline Cigarette smoking (per day) & $10.34(\mathrm{SD} \pm 5.19)$ \\
\hline Biogas exposure (household) & $44(39.3 \% ; \mathrm{M}=5 / 47, \mathrm{~F}=39 / 65)$ \\
\hline SpO & (room air) \\
\hline $\mathrm{FEV}_{1}$ & $75.9 \%(\mathrm{SD} \pm 12.01)$ \\
\hline $\mathrm{FVC}$ & $0.92 \mathrm{~L}(\mathrm{SD} \pm 0.295)$ \\
\hline
\end{tabular}


The majority of the patients were smokers, with only $6(5.4 \%)$ non-smoker. Furthermore, 38 patients $(33.9 \%)$ had exposure to both tobacco smoking and biomass while cooking and heating, of the $33(86.8 \%)$ were female and only $5(13.2 \%)$ were male. 44 patients $(39.3 \%)$ were still using biomass for cooking and heating purpose. Regarding smoking, most of the patients smoked 10 to 14 sticks per day $(n=48,42.8 \%)$, whereas those smoking $>14$ /day were only $25 \%(n=28)$. All the males and the majority of females in the study population were tobacco smokers. Only 6 out of 65 $(9.2 \%)$ females were non-smokers. (Table 1$)$

$\mathrm{SpO}_{2}$ was evaluated in all the patients in the study with a mean $\mathrm{SpO}_{2}$ of $75.9 \%(\mathrm{SD} \pm 12.01)$. In pulmonary function tests, mean $\mathrm{FEV}_{1}$ was $0.92 \mathrm{~L}(\mathrm{SD}=0.295)$ with a minimum of $0.20 \mathrm{~L}$ and a maximum of $1.61 \mathrm{~L}$. (Table 1) Similarly, mean FVC was $1.44 \mathrm{~L}$ $(\mathrm{SD} \pm 0.485)$ with a minimum of $0.29 \mathrm{~L}$ and a maximum of $2.90 \mathrm{~L}$ and mean $\mathrm{FEV}_{1} / \mathrm{FVC}$ ratio was $0.64(\mathrm{SD} \pm 0.057)$ with a minimum of 0.45 and maximum 0.69. Decreased $\mathrm{SpO}_{2}$ was observed in patients with low FEV1 $(\mathrm{p}<0.001)$. Among the study population 30 patients $(26.8 \%)$ had leucocytosis and 3 patients $(2.7 \%)$ had Leukopenia. Neutrophilia was seen in $40(35.7 \%)$ patients and 2 $(1.8 \%)$ patients had neutropenia. Total WBC count and absolute neutrophil count were not statistically significant $(p>0.05)$.

Once the patient becomes stable (after the resolution of exacerbation), ABG value was available for 112 patients. The blood $\mathrm{pH}$ of the patients ranged from 7.23 to 7.48 . Among the study population, the mean blood $\mathrm{pH}$ was $7.34(\mathrm{SD} \pm 0.56)$. Similarly, ABG showed a mean pO2 level of $52.78 \mathrm{mmHg}(\mathrm{SD} \pm$ 5.16), $\mathrm{pCO}_{2}$ of $50.58 \mathrm{mmHg}(\mathrm{SD} \pm 11.77)$, and $\mathrm{HCO}_{3}$ level of $28.37 \mathrm{mEq} / \mathrm{L}(\mathrm{SD} \pm 3.66)$. Age and gender-wise $\mathrm{ABG}$ findings are shown in table 2 .

Table 2: Age and gender-wise findings of arterial blood gas tests among the study population (n=112)

\begin{tabular}{llllll}
\hline & Age group (years) & $\mathbf{p C O}_{2}(\mathbf{m m H g})$ & $\mathbf{p O}_{2}(\mathbf{m m H g})$ & $\mathbf{p H}$ & $\mathbf{H C O}(\mathbf{m E q} / \mathbf{L})$ \\
\hline Male & $<60$ & $46.1(13.2)$ & $55.4(3.04)$ & $7.37(0.561)$ & $27.6(2.98)$ \\
& $60-69$ & $50.27(13.46)$ & $51.8(5.28)$ & $7.34(0.583)$ & $28.0(3.63)$ \\
Female & $70-79$ & $45.57(9.26)$ & $53.21(3.59)$ & $7.37(0.55)$ & $26.4(2.80)$ \\
& $>80$ & $49.9(13.2)$ & $53.7(3.43)$ & $7.35(0.71)$ & $28.27(1.93)$ \\
& $<60$ & $55.6(13.9)$ & $54.3(4.49)$ & $7.31(0.041)$ & $28.57(3.47)$ \\
& $60-69$ & $51.2(11.3)$ & $53.1(4.30)$ & $7.33(0.052)$ & $28.8(3.346)$ \\
& $70-79$ & $53.3(10.97)$ & $50.67(8.08)$ & $7.36(0.05)$ & $29.9(4.55)$ \\
& $>80$ & $50.54(10.4)$ & $52.3(5.36)$ & $7.34(0.590)$ & $28.36(4.68)$
\end{tabular}

Out of 112 patients admitted with COPD with acute exacerbation, 48 patients $(42.9 \%)$ had a wheeze and 64 patients $(57.1 \%)$ had crepitation on auscultation. Chest X-ray was performed and 58 patients $(51.8 \%)$ had COPD related changes, 27 patients $(24.1 \%)$ had opacity and 26 patients $(23.2 \%)$ had infiltration. One patient $(0.9 \%)$ had pleural effusion. $13(11.6 \%)$ patients had positive sputum 1 culture-infective cases, whereas 99(88.4\%) had a negative sputum culture. Various variables were correlated with the number of hospital stay. The mean hospital stay was 7.48 days $(\mathrm{SD} \pm 2.73$ ) with a minimum of 4 days and a maximum of 13 days. There was no significant difference in the duration of hospital stay in both males and females ( $\mathrm{M}=7.06$ days vs. $\mathrm{F}=7.78$ days). A significant correlation was observed with the $\mathrm{pCO}_{2}$ level and length of hospital stay with a p-value $<0.001$. (Table 3 ) Similarly, a significant correlation was observed between $\mathrm{PO}_{2}$ and hospital stay $(\mathrm{p}<0.05)$.

The steroid was prescribed to $61.6 \%$ of patients of COPD with acute exacerbation. However, no significant relationship between steroid use and duration of hospital stay was established ( $\mathrm{p}>0.05)$.

Table 3: Mean hospital stay among in comparison to $\mathrm{CO}_{2}$ level

\begin{tabular}{lll}
\hline $\mathrm{CO}_{2}$ level & Mean hospital stay (days) & p-value \\
\hline Normocapnia & $6.13(\mathrm{SD} \pm 2.13)$ & $<0.001$ \\
Hypercapnia & $8.79(\mathrm{SD} \pm 2.58)$ &
\end{tabular}

Logistic regression was performed to see the effect of ABG in the duration of hospital stay for which 5 days cut off value was considered. The type of respiratory failure and $\mathrm{pH}$ of blood showed significant findings. The patients without respiratory failure were discharged earlier (5.09 days) than type I respiratory failure and type II respiratory failure (Table 4) with significant $\mathrm{p}$-value $(\mathrm{p}<0.001)$. Similarly, the $\mathrm{p}$-value for blood $\mathrm{pH}$ was $<0.05$.

Table 4: Mean hospital stay among various arterial blood gas findings

\begin{tabular}{lll}
\hline Respiratory failure & Mean Hospital stay (Days) & p-value \\
\hline Type 1 & 6.04 & \\
Type 2 & 9.88 & $(<0.001)$ \\
Overall Mean & 7.48 & \\
\hline & & \\
\hline & DISCUSSION \\
\hline
\end{tabular}

COPD is one of the major public health problems around the world and acute exacerbation of COPD is the major cause of significant morbidity and mortality worldwide. Though the prevalence varies in different countries along with the age and sex of an individual, COPD is going to be the fifth leading cause of disability and the third leading cause of death worldwide by 2020. ${ }^{11}$ According to the study conducted by Dhimal et al in a different part of Nepal, the Prevalence of COPD was $11.7 \%$. $^{12}$

Respiratory failure is a common and important event, which is frequently associated with severe exacerbations of COPD. ${ }^{13}$ The higher mortality rate is associated with the presence of hypercapnia in respiratory failure. ${ }^{14}$ Changes in lung mechanics are believed to be the significant determinants of the physiological variations from the norm that describe hypercapnic respiratory failure. A subject would need to expand their ventilation to overcome the wasted ventilation in high ventilation/perfusion ratio units, 
however, their failure to do so regardless of the respiratory boost that a rising $\mathrm{CO}_{2}$ strain gives has been the subject of a lot of discussions. ${ }^{15}$

In this study, among 112 patients, 47(41.96\%) were male and $65(58.04 \%)$ female. Similar findings were observed in a study done by Ghosh $\mathrm{V}$ et al. ${ }^{16}$ which had $59.6 \%$ female patients in comparison to $40.4 \%$ male patients. One reason could be increased exposure to biomass among females, due to involvement in household cooking. In contrast, Dhimal et al, in their study, concluded male predominance among patients with COPD. ${ }^{12}$

The plausible hypothesis regarding increased incidence among females might be a genetic predisposition for smoking-related lung changes in certain families. Silverman et al, in his study of 84 probands, not only observed high prevalence among females (71.4\%) but also had an almost double risk of having obstructive lung disease. ${ }^{17}$ Studies with an animal had shown the role of Estrogen in the metabolism of tobacco-smoke. In the animal model; estrogen upregulated the cytochrome p-450 enzymes; which plays a role in increasing susceptibility to cigarette smokerelated oxidant injury in the lung parenchyma. ${ }^{17}$ Anatomically, Females have smaller lung and airways compared to males, hence, with the same amount of exposure to smoking they are more prone to develop the disease. ${ }^{18}$

Cigarette smoking is a well-established cause for COPD followed by biomass exposure in a country like Nepal and India. ${ }^{4,19}$ Among the study population, $94.6 \%$ were smokers whereas the rest were non-smokers. $33.9 \%(\mathrm{n}=38)$ patients had a history of both tobacco smoking and biomass exposure of which $33(86.8 \%)$ were female whereas only 5(13.2\%) were male. Among 112 patients, 39.3\% of patients still had a history of biomass exposure. Among total study patients, all male patients were tobacco smokers whereas only $9.23 \%$ of females were non-smokers.

A significant association between $\mathrm{SpO}_{2}$ and $\mathrm{FEV}_{1}$ was found $(\mathrm{p}<0.001)$, unlike other studies where there was no significant correlation between $\mathrm{FEV}_{1} \%$ predicted and $\mathrm{SpO}_{2}$ values. ${ }^{20,21}$ $\mathrm{FEV}_{1}$ value was compared with the hospital stay which showed a consistent and important association of decreasing $\mathrm{FEV}_{1}$ (increasing severity of COPD stage) with the prolonged hospital (p-value - 0.004). A similar finding was found in the study done by Sijapati et al. ${ }^{22}$

In this study, as compared to Type 1 respiratory failure, the patients with type 2 respiratory failure had prolonged hospital stay $(\mathrm{p}<0.001)($ Table 4$)$. This may be because of the intervention needed to washout the $\mathrm{CO}_{2}$ utilizing either Invasive or noninvasive ventilator supports Other studies also have findings similar to ours. ${ }^{14,22,23}$ A study done by Nousheen et al observed that hypercapnic patients had a longer hospital stay (mean $9.27 \pm 7.57$ days), increased requirement for non-invasive mechanical ventilation on admission $(\mathrm{n}=45 ; 78.94 \%))$, and longer mean time to clinical stability ( $4.39 \pm 2.0$ days) compared with the other groups. ${ }^{24}$ Hypercapnic patients had a longer duration of hospital stay in comparison to normocapnic patients (Table 3).

Among $61.6 \%$ of our patients receiving steroids, no significant change in the duration of hospital stay was observed ( $p>0.05)$. Scholl et al, in his study done at Colorado Hospital between July 1, 2012, and May 20, 2016, included AECOPD patients (89 in the steroid group and 49 in the non-steroid group). No significant difference was seen in the mean duration of hospital stay $(4.7 \pm 3.2$ versus $4.2 \pm 2.1$ days, $\mathrm{p}=0.27) .{ }^{25}$ In contrary to this and our study, Woods et al experienced a significantly shorter length of hospital stay in comparison to placebo ( 8.5 vs. 9.7 days, $\mathrm{P}=0.03$ ) ${ }^{26}$ The role of steroids in the length of hospital stay has to be studied further.

\section{CONCLUSIONS}

COPD is a complex and progressive lung disease associated with significant morbidity and mortality. Increased length of hospital stay is seen in hypercapnic patients suffering from AECOPD with type II respiratory failure, Hence, aggressive early management to correct hypercapnia may lead to a shortened hospital stay and thus, better outcome. For that, type II respiratory failure should be considered as one of the important criteria to flag the patient and manage accordingly. However, further large-scale studies are required to confirm the observed findings of this study.

\section{REFERENCES}

1. Nepal Health Research Council (NHRC), Ministry of Health and Population (MoHP) and Monitoring Evaluation and Operational Research (MEOR). Nepal Burden of Disease 2017: A Country Report based on the Global Burden of Disease 2017 Study. Kathmandu, Nepal: NHRC, MoHP, and MEOR; 2019. (Cited on $2^{\text {nd }}$ October 2019) Available from: Website

2. World Health Organization. Chronic obstructive pulmonary disease (COPD). 2017. (Cited on ${ }^{\text {st }}$ October 2019). Available from: Website

3. Adeloye D, Chua S, Lee C, Basquill C, Papana A, Theodoratou E, et al. Global Health Epidemiology Reference Group (GHERG). J Glob Health. 2015; 5(2):020415. Crossref

4. World Health Organization. WHO Report on the Global Tobacco Epidemic, 2008: The MPOWER Package. Geneva: World Health Organization; 2008. (Cited on $1^{\text {st }}$ October 2019). Available from: Website
5. Adhikari TB, Neupane D Kallestrup. Burden of COPD in Nepal. Int J Chron Obstruct Pulmon Dis. 2018; 13: 583-9. Crossref

6. Global Strategy for the Diagnosis, Management and Prevention of COPD, Global Initiative for Chronic Obstructive Lung Disease (GOLD) 2017. [Cited on $2^{\text {nd }}$ October, 2019]. Available from: Website

7. Celli BR, Cote CG, Marin JM, Casanova C, Montes de Oca M, Mendez RA, et al. The body-mass index, airflow obstruction, dyspnea, and exercise capacity index in chronic obstructive pulmonary disease.N Engl J Med. 2004; 350(10):1005-12. Crossref

8. Freeborne N, Lynn J, Desbiens NA. Insights about dying from the SUPPORT project. The Study to Understand Prognoses and Preferences for Outcomes and Risks of Treatments. J Am Geriatr Soc 2000;48: Suppl. 5 S199-S205. Website

9. Celli BR, Cote CG, Marin JM, Casanova C, Montes de Oca M, Mendez RA, et al. The body-mass index, airflow obstruction, dyspnea, 
and exercise capacity index in chronic obstructive pulmonary disease. N Engl J Med 2004;350:1005-1012. Crossref

10. Seneff MG, Wagner DP, Wagner RP, Zimmerman JE, Knaus WA. Hospital and 1-year survival of patients admitted to intensive care units with acute exacerbation of chronic obstructive pulmonary disease. JAMA 1995;274:1852-1857. Website

11. Raherison C, Girodet PO. Epidemiology of COPD. European Respiratory Review 2009;18:213-21. Website

12. Dhimal M, Karki KB, Sharma SK, Aryal SK, Aryal KK, Shrestha N, et al. Prevalence of Selected Chronic Non-Communicable Diseases in Nepal. J Nepal Health Res Counc. 2019;17(44):394-401. Website

13. Hurd S, Anzueto A, Barnes PJ, Buist SA, Calverley P. Global strategy for the diagnosis, management, and prevention of chronic obstructive pulmonary disease: GOLD executive summary. Am J Respir Crit Care Med 2007;176:532-55. Website

14. Connors AFJ, Dawson NV, Thomas C, Harrell FE Jr, Desbiens N, Fulkerson WJ, et al. Outcomes following acute exacerbation of severe chronic obstructive lung disease. The SUPPORT investigators. Am J Respir Crit Care Med 1996; 154: 959-967. (Erratum in) Am J Respir Crit Care Med 1997;155:38. Website

15. Seneff MG, Wagner DP, Wagner RP, Zimmerman JE, Knaus WA. Hospital and 1-year survival of patients admitted to intensive care units with acute exacerbation of chronic obstructive pulmonary disease. JAMA 1995; 274: 1852-7. Website

16. Ghosh V, Lamichhane S, Thakuri S, Khadka K, Teli S, Adhikari S, et al. Study on Epidemiology of Chronic Obstructive Pulmonary Disease (COPD) at Western Regional Hospital, Pokhara. Journal of Gandaki Medical College-Nepal, 2017;9(2):65-9. Crossref

17. Silverman E, Weiss S, Drazen J, Chapman HA, Carey V, Campbell EJ, et al. Gender-related differences in severe, early-onset chronic obstructive pulmonary disease. Am J Respir Crit Care Med. 2000;162:2152-8. Crossref
18. LoMauro A, Aliverti A. Sex differences in respiratory function. Breathe (Sheff). 2018; 14(2):131-40. Crossref

19. Koul PA. Chronic obstructive pulmonary disease: Indian guidelines and the road ahead. Lung India. 2013;30(3):175-7. Crossref

20. Kelly AM, McAlpine R, Kyle E. How accurate are pulse oximeters in patients with acute exacerbations of chronic obstructive airways disease? Respir Med 2001;95:336-40. Website

21. Ardestani ME, Abbaszadeh M. The association between forced expiratory volume in one second (FEV1) and pulse oximetric measurements of arterial oxygen saturation $(\mathrm{SpO} 2)$ in the patients with COPD: A preliminary study. J Res Med Sci 2014;19:257-61. $\underline{\text { Website }}$

22. Sijapati MJ Bhatta N, Khanal B, Lamsal M, Chaudhary S. Study of factors determining outcomes in the hospitalized patients with acute exacerbation of chronic obstructive pulmonary disease (COPD). Journal of Universal College of Medical Science 2014;02(02):28-32. Website

23. Anderson F, Brog S, Jansson SA, Jonsson AC, Ericsson A, Prütz C, Rönmark E, Lundbäck B. The Costs of Exacerbation in Chronic Obstructive Pulmonary Diseases (COPD). Respir Med 2002;96:7008. $\underline{\text { Crossref }}$

24. Iqbal N, Irfan M, Zubairi ABS, Awan S, Khan JA. Association of hypercapnia on admission with increased length of hospital stay and severity in patients admitted with community-acquired pneumonia: a prospective observational study from Pakistan. BMJ Open 2017;7:e013924. Crossref

25. Scholl T, Kiser TH, Vondracek SF. Evaluation of Systemic Corticosteroids in Patients With an Acute Exacerbation of COPD and a Diagnosis of Pneumonia. Chronic Obstr Pulm Dis. 2018;5(1):5765. Crossref

26. Woods JA, Wheeler JS, Finch CK, Pinner NA. Corticosteroids in the treatment of acute exacerbations of chronic obstructive pulmonary disease. Int J Chron Obstruct Pulmon Dis. 2014;9:421-430. $\underline{\text { Crossref }}$ 